\title{
Crise e prosa em Sob o olhar de Neptuno, de Manuel de Freitas
}

\section{Crisis and prose in Sob o olhar de Neptuno, by Manuel de Freitas}

Tamy de Macedo Pimenta ${ }^{1}$

\begin{abstract}
Resumo:
O artigo pretende discutir como o livro Sob o olhar de Neptuno, publicado em 2018 pelo poeta português contemporâneo Manuel de Freitas, mobiliza a história, a tradição literária e a crítica portuguesas, colocando-as em crise por meio do diálogo com Os Lusíadas e pela exploração da ideia de prosa em seus poemas.
\end{abstract}

Palavras-chave: Poesia. Manuel de Freitas. Crise. Poesia portuguesa contemporânea.

\section{Abstract:}

This article intends to discuss the ways by which Sob o olhar de Neptuno, published in 2018 by the Portuguese contemporary poet Manuel de Freitas, dislocates Portuguese History, literary tradition and criticism, putting them into crisis by the dialog with Os Lusíadas and by the exploration of the Ideia of prose in his poems.

Keywords: Poetry. Manuel de Freitas. Crisis. CONTEMPORARY PORTUGUESE POETRY. 
No mais interno fundo das profundas

Cavernas altas, onde o mar se esconde,

Lá donde as ondas saem furibundas Quando às iras do vento o mar responde,

Neptuno mora e moram as jocundas Nereidas e outros Deuses do mar, onde As águas campo deixam às cidades Que habitam estas húmidas Deidades. Luís de Camões (Lus., VI, 8)

É no reino marítimo de Netuno que Baco, ignorado pelos deuses do Olimpo, busca apoio contra "os humanos, fracos e atrevidos" (Lus., VI, 28) representados pela frota de Vasco da Gama a caminho das Índias no poema épico camoniano. Enfurecido pelo relato do deus do vinho e temendo que, tamanha a ousadia dos lusitanos, estes "Que do Mar e do Céu, em poucos anos,/ Venham Deuses a ser, e nós [deuses], humanos" (Lus., VI, 29), Netuno decide investir contra os navegantes portugueses. Todavia, por meio da intervenção de Vênus, as ninfas convencem os ventos amorosamente a suspenderem a forte tempestade, restando às divindades marítimas somente assistir ao fim das "ondas de Neptuno furibundo" (Lus., VI, 76) e a mais uma gloriosa vitória de Gama e seus nautas.

Os Lusíadas, poema épico tecido em contradições, cujo Poeta tem em uma "mão sempre a pena e noutra a espada" (Lus, VII, 79, 8), não se restringem a cantar as glórias lusitanas sobre o mar. Assim, se por um lado, o poema narra os feitos da frota liderada por Vasco da Gama, por outro, ele também aponta para os problemas que o projeto de expansão marítima português suscita, seja por meio da voz de Adamastor, o gigante transformado em cabo, que conta aos navegantes "os danos de mi que apercebidos/ Estão a teu sobejo atrevimento,/ Por todo o largo mar e pola terra/ Que inda hásde sojugar com dura guerra." (Lus., V, 42); seja pelo discurso do Velho do Restelo à beira do Tejo a denunciar a "vã cobiça" portuguesa que trará mortes, perigos e tormentas ao povo; seja pela própria voz do Poeta, que 
reconhece em vários pontos de seus excursos a dificuldade de cantar "a gente surda e endurecida/ [...] que está metida/ no gosto da cobiça e na rudeza/ duma austera, apagada e vil tristeza" (Lus., X, 145, 1-8).

Desse modo, por mais que demonstre o triunfo da empreitada de Gama, o poema ganha contornos trágicos - e, por isso, trata-se de poema épico altamente contraditório e moderno -, ao apontar para as consequências negativas que a expansão marítima trará para Portugal. Consequências que, em seu conjunto, se estenderão muito além do século XVI e que Camões, embora tenha antevisto e presenciado parte delas, não vivenciará. $O$ poeta, que morre em situação de pobreza, também não presenciará a monumentalização de sua figura - inclusive por meio de estátuas e de um túmulo com ossos alheios - e a apropriação de versos d'Os Lusiadas para justificar e servir de exemplo a outras empreitadas portuguesas além-mar no período salazarista. Como lembra o poeta e crítico Luis Maffei, há um "ainda vigente e equivocado consumo que se faz do legado camoniano" (MAFFEI, 2005, p. 317), ao qual escritores como Jorge de Sena, António Lobo Antunes, dentre outros, pretendem se contrapor por meio de obras que buscam resgatar a dimensão humana - o homem, não o monumento - de Camões. Essa é a corrente à qual procura se juntar Manuel de Freitas, poeta português cujo primeiro livro data dos anos 2000. Tal linha de pensamento, enquanto se contrapõe radicalmente em relação a alguma poesia chegada a "anacronismos e ourivesarias" (FREITAS, 2002, p. 12), se mantém próxima, recolhendo "com bastante atenção, sem abrir mão de alguma reverência, diversos nomes consagrados, sobretudo Camões" (MAFFEI, 2005, 307).

\section{Em mares incertos}

O gesto de ir ao encontro de Camões e, ao mesmo tempo, de encontro com certa leitura do poeta e sua obra não é fortuito, muito menos 
surpreendente, quando levamos em conta o trajeto poético-crítico de Freitas. Tanto em seus ensaios quanto em seus poemas, o poeta sempre buscou se posicionar de forma crítica em relação à tradição literária portuguesa, desde obras que lhe são mais próximas temporalmente até aquelas que remontam aos textos mais clássicos, dentro das quais se encontra a epopeia de Luís de Camões. Esse posicionamento, embora por vezes expresso de maneira provocativa ou insultuosa, ${ }^{2}$ parece-nos, porém, mais próximo de uma tentativa de pôr a literatura portuguesa em crise, enervando-a, conforme o termo é pensado pelo também poeta-crítico Marcos Siscar, ao refletir sobre a "crise de vers" de Mallarmé:

[...] a crise de verso não designa uma interrupção ou um colapso histórico do verso; antes, uma irritação do verso, dentro do verso, e a propósito dele. Uma crise de verso, como se pode notar nas referências dadas pelo ensaio, que generaliza a ideia de verso, é a situação na qual ele se manifesta irritado, enervado, em estado crítico. (SISCAR, 2010, p. 107-108)

Assim, entendemos que os procedimentos irônicos de aproximação/ distanciamento em relação a Os Lusíadas utilizados por Freitas procuram trazer o poema camoniano - e toda a tradição dele derivada - a um estado crítico, no sentido de dramatizá-lo ${ }^{3}$ ante o tempo presente, em vez de simplesmente tentar apagá-lo ou superá-lo. Exemplo disso é o poema Camões burguer, de Game Over, que, desde seu título, aponta para o fato de "que se come, ainda, e mal, a memória do poeta, sem nenhum vestígio de qualquer lógica antropofágica" (MAFFEI, 2005, p. 317):

2 Basta nos lembrarmos do prefácio Tempo dos puetas na antologia Poetas sem qualidades (2002), assinado por Manuel de Freitas ou de poemas tais como Inventário plebeu, do qual cito apenas as duas primeiras estrofes: "A verdade, digam lá o que disserem,/é que tivemos muito pouca sorte/com os poetas (?) nossos contemporâneos.//Um nasceu em Galveias e tatua-se/ ou alfineta-se para disfarçar um vazio evidente;/outro gosta de andar nu em Braga,/muito depois - e aquém - de qualquer Pacheco./(Ignoram, ambos, que a única pila maior/do que o mundo era a do João César Monteiro.)" (FREITAS, 2012, p. 27).

3 Siscar faz uso desse verbo para argumentar sobre os méritos do movimento concretista no Brasil: "Dramatizando a questão do verso, colocando-a na ordem do dia, o Concretismo teve o inegável mérito não de superar o verso, nem mesmo de fazer dele uma 'opção', mas justamente evitar que se faça verso por inércia." (SISCAR, 2010, p. 106, grifos do autor). 
É conforme. Já lá vão mais de quatrocentos anos de tal "conversa fiada" que poucas penélopes encontrou. Para alguns, doutos e moralíssimos, o comércio com as musas não era compatível com fodas de foder bem dadas, em redondilhas um pouco maiores do que eles, os necrófagos de serviço.

Os tempos mudaram, claro (e as vontades foram encontrando novos alvos), mas a comédia dos ossos veio para ficar, incerta, numa praia insigne de enganos e misérias.

Agora, num intervalo cibernáutico medido pela ignorância pública, lembram-se d'O Poeta e de uns versos que a memória canta, propícios às presidências que tão mal presidem.

São gajos novos, ou nem tanto assim, místicos do "progresso" em que seus redondos cus assentam, isto é, sobre um povo analfabeto e tudo que ainda não lê nem sonha a pátria que foi, apenas, pretexto.

Porque um homem, por menos que valha, valerá sempre mais do que esse conluio de gestos sem alma dentro. A pátria, meus senhores a pátria, foi esse ocidental falo lusitano que gostava como Pessoa de vinhos e de ironia fera. O resto foi cuspir, cuspir raro na inércia e no inconclusivo ardor com que um país em saldo se cumpre. (FREITAS, 2017, p. 47)

Como bem apontado por Ana Beatriz Affonso Penna, os versos acima reiteram: 
uma vertente seniana de recuperação e consequente humanização da memória de Camões que objetiva a crítica da apropriação do poeta por projetos deturpadores de sua poesia. Os burgers, exemplo maior da comida fast food, os quais podem ser preparados e servidos rapidamente, apesar de desfrutarem de preço modesto, possuem qualidade nutricional baixíssima. Consumidos como hambúrgueres de uma rede fast food, os versos camonianos, ainda tão "propícios às presidências que tão mal presidem", continuam, mesmo depois de "quatrocentos anos de tal "conversa fiada", a servirem a "místicos do "progresso"” de "um povo analfabeto". (PENNA, 2012, p. 8)

Contra esse mau consumo dos versos do poeta, Manuel de Freitas recupera a herança camoniana não só por meio de poemas cujo diálogo com o poeta é mais evidente (como em "Camões burguer" e outros), mas sobretudo por meio da criação de uma poética que, assim como a de Camões, deixa ver as contradições do tempo presente:

Contra a inserção de Camões na lógica de consumo mercantil do fast food, através de um tratamento do poético que escamoteia a materialidade, ergue-se uma poesia que restaura a dimensão do valor econômico, problematizando sua relação com a arte e com o mundo. (PENNA, 2012, p. 9).

É nesse sentido que acredito ser possível entrever mais um diálogo entre as obras freitasiana ${ }^{4}$ e camoniana em Sob o olhar de Neptuno, pequeno livro composto por quatro poemas, publicado em 2018. Nele, Freitas insere a figura imponente e mitológica do deus dos mares não só no título, mas também na capa do livro, elaborada por Ângelo Ferreira de Sousa, com

4 O termo foi empregado pelo poeta e crítico Luís Maffei, em ensaio sobre Manuel de Freitas para a coleção Ciranda da Poesia, de 2014. 
o corpo ilustrado em preto, branco e um pouco de dourado (dando-lhe um aspecto de algo poderoso e antigo, mas que agora está aos poucos se deteriorando) e os braços abertos, parecendo querer alcançar algo com a mão esquerda. $\mathrm{O}$ topo da cabeça está posicionado entre o nome do autor e o título do livro, o que possibilita uma outra e interessante leitura: "Manuel de Freitas sob o olhar de Neptuno".

Figura 1 - Detalhe da capa do livro Sob o olhar de Neptuno

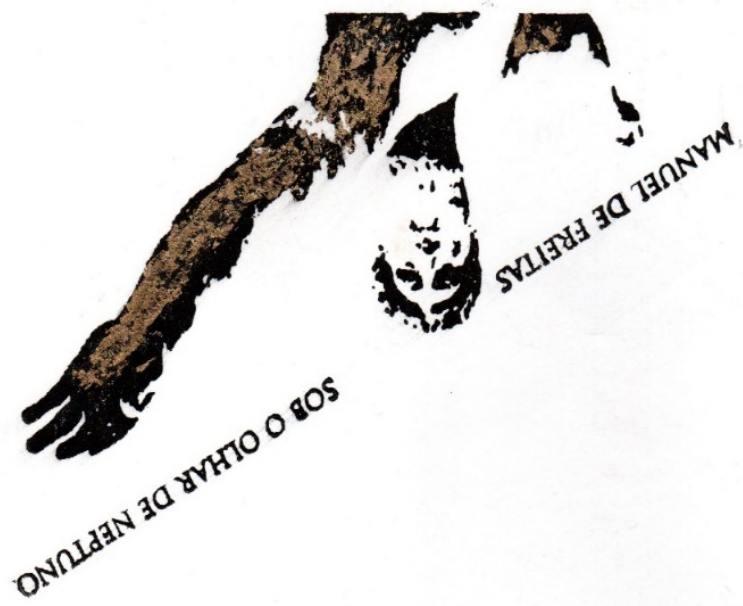

Fonte: FREITAS, 2018.

Mas o que vê, afinal, o deus dos mares nessas páginas? Ao abrirmos o livro, dedicado à professora Ana Isabel Soares, que exerce sua docência na Universidade de Algarve, deparamo-nos justamente com pequenos textos constituídos pela paisagem algarvia que nos permitem entrever uma imagem portuguesa bastante diversa da visão que Netuno tem dos nautas 
da frota de Vasco da Gama n'Os Lusíadas. Mais próximos dos excursos do Poeta ou da fala do Velho do Restelo, os versos de Sob o olhar de Neptuno enxergam as ruínas da história portuguesa, aqui trazidas, por exemplo, de forma metonímica por meio das Ruínas de Milreu:

\begin{abstract}
É muito fácil, em Milreu, pisar involuntariamente uma formiga agigantada, embora pequena se comparada com o que resta do templo ou com as douradas transcritas para mosaico cuja cor se foi esbatendo. Também é fácil tocar ou pisar pedrinhas soltas ou conchas dispostas em espiral no que seria o centro exacto do templo. Mais difícil é perceber o que herdámos realmente de tantos séculos, o que aprendemos ou desaprendemos com aquilo a que chamamos história. Deus, caso andasse por ali, habitaria as laranjeiras, separado de nós por umas grades. (FREITAS, 2018, p. 5)
\end{abstract}

É interessante notar, nesse texto, a imagem da "formiga agigantada" que nos lembra, ao mesmo tempo, o "Bicho da terra tão pequeno" (Lus., I, 106) e o momento histórico das navegações que permitiu, por algum tempo, que a formiga se tornasse "agigantada". Contudo, como sabemos, essa formiga estava fadada a um declínio por ela mesma forjado, como a voz do Poeta nos alerta em várias partes da epopeia camoniana. Imagem metonímica de tal percurso, o templo em Milreu, semelhantemente ao grande Império português - e à imagem de Neptuno na capa do livro deteriorou-se e tem sua cor esbatida. Perceber isso ou "tocar ou pisar pedrinhas soltas ou conchas dispostas em espiral", diz-nos o poema, é fácil se comparado à difícil tarefa de "perceber o que herdámos realmente de tantos séculos, o que aprendemos ou desaprendemos com aquilo a que chamamos história". O caminho para encarar essa difícil tarefa é encarar as ruínas, materiais e históricas: "Tudo em ruínas,/ a infância, o país perdido", escreveu outro poeta português, Joaquim Manuel Magalhães (1981, p. 51).

Perceber as ruínas, os pequenos destroços, em meio à paisagem 
que se habita, configura-se como um modo de colocar a herança histórica (e também a literária) em crise. E, para fazê-lo dentro do poema, irritando o verso conforme escreveu Siscar, Freitas opta por um uso diferenciado da poesia, a qual, também em ruína, se dilui nesse e em outros textos de Sob o olhar de Neptuno, indo em direção à prosa. Embora o lirismo e o ritmo presentes em suas linhas nos remetam ao gênero poético, a ausência do verso causa estranhamento, sobretudo dentro de uma obra, como a de Manuel de Freitas, que, mesmo pregando o fim de uma retórica "tardomallarmeneana"s, mantém-se fiel ao emprego do verso em seus livros anteriores. Se nos apoiarmos na reflexão de Giorgio Agamben em seu curto texto, homônimo do livro do qual faz parte, Ideia de prosa, perceberemos que poesia e prosa se complementam dentro da própria estrutura do verso, já que:

O verso, no próprio acto com o qual, quebrando um nexo sintáctico, afirma a sua própria identidade, é, no entanto, irresistivelmente atraído para lançar a ponte para o verso seguinte, para atingir aquilo que rejeitou fora de si: esboça uma figura de prosa, mas com um gesto que atesta a sua versatilidade [...]. O enjambement traz, assim, à luz o andamento originário, nem poético, nem prosaico, mas, por assim dizer, bustrofédico da poesia, o essencial hibridismo de todo discurso humano. (AGAMBEN, 1999, p. 32)

Assim, essa tensão entre poesia e prosa torna a delimitação dos limites de cada uma dessas manifestações uma ambição impossível e improdutiva e, consequentemente, desloca a relação entre ambas para um domínio mais interessante: o de reconhecer as "figuras de prosa" como constituintes de um trabalho poético que põe o verso em crise. De acordo

5 Uso o termo empregado por Freitas no prefácio da polêmica antologia Poetas sem qualidades: "O que, de alguma maneira, aproxima estes nomes (e legitimará, porventura, reuni-los num mesmo livro) são, precisamente, as várias 'qualidades' que notoriamente não possuem. Estes poetas não são muita coisa. Não são, por exemplo, ourives de bairro, artesãos tardo-mallarmeanos, culturalizadores do poema digestivo, parafraseadores de luxo, limadores das arestas que a vida deveras tem." (FREITAS, 2002, p. 14, grifos do autor) 
com Florencia Garramuño (2014), alguns poemas muito recentes (a autora utiliza em seu texto os exemplos de Monodrama, de Carlito Azevedo, e El eco de mi madre, de Tamara Kamenszain), atravessados por uma forte pulsão narrativa e uma decidida vontade de transgredir de formas variadas os limites do lírico, parecem estar pondo em evidência toda essa problematização. De maneira semelhante, no contexto português, a crítica Rosa Maria Martelo tem observado de forma recorrente em seus textos ${ }^{6}$ a presença marcante de uma narratividade na poesia publicada a partir dos anos 1990, poesia que tem buscado inventar uma linguagem "limpa" e "comunicante" (MARTELO, 2003, p. 52). A construção dessa linguagem poética passa, então, por uma aproximação da prosa, que invade o poema lhe trazendo o que o poeta francês Pierre Alféri chama de "ideal baixo da literatura" (ALFÉRI, 2013, p. 425). Tornando-se cada vez menos um gênero, a prosa nesse sentido se assemelha mais a um ideal a ser buscado na escrita de poesia a fim de criar novos sentidos:

[...] Esse horizonte, essa ideia, por mais livres e amplos que sejam, convocam uma política (portanto, uma crítica) da literatura. Sem prejulgar essa política por vir, falar da literatura enquanto prosa deve permitir - de novo, a partir de agora, enquanto se espera - evocar um trabalho, programas de escrita complexos, precários, sem que por isso se busque apoio em categorias estilísticas; e evocar um modo, mil modos que os livros têm de se afinarem com a "prosa do mundo", sem que por isso se fale de temas (não há temas) [...]. Ela jaz nos meandros da sintaxe e na violência dos cortes, esperta, bruta; todos os golpes estão valendo, exceto os que já foram dados. (ALFÉRI, 2013, p. 427)

Destarte, o caráter prosaico assumido por Freitas em Sob o olhar de Neptuno (e que pode ser observado em outras obras do poeta) não se

6 Cf. MARTELO, Rosa Maria. Reencontrar o leitor. Relâmpago: revista de poesia, Lisboa, v. 12, p. 39-52, 2003; MARTELO, Rosa Maria. Anos noventa: breve roteiro da novíssima poesia portuguesa. Via Atlântica, São Paulo, n. 3, Não paginada, 1999. 
estabelece pela opção da escrita de poemas em prosa, até porque, como veremos mais adiante, nem todos os quatro poemas do livro seguem essa forma. Pelo contrário, esses poemas se aproximam do ideal de prosa defendido por Alféri ao proporem um modo de fazer poesia que se afina com a "prosa do mundo" por meio de um trabalho crítico, político e poético que coloca a herança histórico-literária portuguesa em crise.

Além disso, é importante ressaltar que esse trabalho se faz não lançando mão de reflexões filosóficas ou construções retóricas abstratas, mas por meio de motivos prosaicos, ligados a circunstâncias banais do cotidiano. Como bem apontou Rosa Maria Martelo-embora não se referindo à poesia de Freitas, mas a um conjunto de poetas dos anos 90 que em muito se aproximam desta -, "Esta atenção por circunstâncias ocasionais, subitamente reveladoras, prende-se também com a desmontagem do discurso quotidiano (como se a poesia se revelasse na vigilância dos registos habitualmente menos vigiados)." (MARTELO, 1999). Exemplo disso, Fora da Vila, poema que abre Sob o olhar de Neptuno, nos apresenta com uma cena trivial que, ainda que possa parecer, à primeira vista, um mero relato de uma tarde vivenciada pelo sujeito poético, traz o algo a mais que transforma a circunstância em poesia:

$<<$ Existe um nome para tudo $>>-$ disse-nos um pouco aturdida a empregada do 'Vilmar', a propósito de gambas, camarão e lingueirões. Percebia-se que, para ela, os nomes eram bem menos importantes do que as coisas, os sabores, o mundo - que cabe, por vezes, numa viela de Faro. Entre cegonhas, andorinhas e melgas demasiado traiçoeiras.

A tarde de alfarroba e laranja veio acompanhada por um jarro de licor de figo que poderia ter sido inventado por Morandi. Se há, de longe em longe, tardes perfeitas sobre a terra, esta foi uma delas, junto de um mar retalhado. (FREITAS, 2018, p. 3) 
Iniciado in media res, com uma voz associada à "empregada do 'Vilmar",, o poema, partindo de uma circunstância a qual os leitores não têm acesso, deixa lacunas que permanecem impreenchíveis e que, ao mesmo tempo, trazem o leitor para dentro desse quadro com uma mulher dizendo algo a um "nós" ao qual o leitor parece ser convidado a se juntar. Nessa direção, o próprio poema se torna uma circunstância, já que esta é criada conforme a leitura se faz, por meio de um movimento que traz o poema para a esfera do comum, do partilhável, longe de uma metafísica que valoriza os nomes em detrimento das coisas em si mesmas: "Percebiase que, para ela, os nomes eram bem menos importantes do que as coisas, os sabores, o mundo". Não é por acaso que a situação relatada seja a de uma alimentação compartilhada, na qual os frutos do mar e as bebidas sobre a mesa são descritos com mais precisão do que as personagens que delas se alimentam - são os objetos partilhados, em seus sabores, cores e cheiros, os protagonistas do poema. E são eles que são observados por Neptuno, metonimicamente figurado no "mar retalhado" - e, portanto, em pedaços que se n'Os Lusíadas assistiu às conquistas marítimas portuguesas, agora contempla os pormenores de uma tarde lusitana à beira-mar.

\section{Calmaria}

Ao escrever sobre o haiku na obra de Matsuo Bashô, Octavio Paz enfatiza a ligação desse tipo de poesia com o zen-budismo e com o entendimento da coexistência entre vida e morte. Nessa perspectiva, segundo Paz, "o homem não é unicamente escravo do tempo e da morte, mas leva dentro de si um outro tempo" (PAZ, 2009, p. 167); tempo este que se encontra na poesia. Em meio ao que poderíamos chamar de três petits poèmes en prose, para recordar Baudelaire, encontramos, no livro de 
Freitas, um haiku:

\author{
A flor da ameixa \\ apenas se revela \\ na curva da alface. \\ (FREITAS, 2018, p. 4)
}

Por meio da curvatura de um elemento (no poema, a alface), algo é revelado (a flor da ameixa). Entretanto, essa revelação só ocorre por meio dessa curva. Seria possível levarmos essa reflexão para um outro entendimento do tempo? Ou para um outro entendimento da história? Se optarmos por seguir esse percurso de pensamento, poderíamos ver na curva do poema - em seu desvio, enervamento, crise - um modo diferenciado de olhar e perceber o tempo. Passado, presente e futuro.

Sem ter a pretensão de fixar ou alterar o tempo, os poetas podem ao menos - como o fez Camões - tentar responder a ele, mostrando suas contradições e se posicionando em relação a ele, criando "mil modos [...] de se afinarem com a 'prosa do mundo' por meio da escrita de poesia. Um desses modos explorado por Manuel de Freitas é construir poemas que se demoram em circunstâncias passageiras e que, através dessa lentidão, interrompem, como bem ressaltou António Guerreiro, aquilo que está diante de nossos olhos com "o golpe da magia poética" (GUERREIRO, 2003, p. 17):

Não faltam, em Portugal, sítios tão dolorosamente parados como São Brás de Alportel. Gosto de alguns deles, tão contrários à vertigem económica do país e a velocidades puramente artificiais. Os homens sentam-se, bebem cerveja ou cravam cigarrilhas, olham resignados os prédios demolidos ou os novíssimos supermercados. Preferimos, desta vez, não parar em Barrabés. Mas encontrámos, quase sem querer, 
a Cova do Lobo. Pode-se fugir de tudo, menos da infância.

(FREITAS, 2018, p.6)

Afinal, talvez tenha sido esse o mesmo olhar do Velho do Restelo n'Os Lusíadas ao ver os navegantes lusitanos se deixarem ir para longe da Pátria em nome da ambição e da cobiça. Se Camões, por meio da escrita de uma epopeia que fugia em vários aspectos aos moldes clássicos, ressaltou as falhas a que se entregaram os portugueses através da voz de algumas personagens - dentre as quais o próprio Velho - e de seus excursos; Manuel de Freitas, em diálogo crítico e atento com a obra camoniana, ressalta em Sob o olhar de Neptuno tanto as ruínas deixadas pelo passado quanto as trazidas no presente português, proporcionando questionamentos e reflexões fundadas em uma poética que põe em crise a própria ideia de poesia por meio do diálogo com a tradição histórico-literária portuguesa.

\section{Referências:}

AGAMBEN, Giorgio. Ideia da prosa. Tradução. João Barrento. Lisboa: Cotovia, 1999.

ALFERI, Pierre. Rumo à prosa. Alea, Rio de Janeiro, v. 15, n. 2, p. 423-430, Dec. 2013. Disponível em: http://www.scielo.br/scielo.php?script=sci arttext\&pid=S1517-106X2013000200011\&lng=en\&nrm=iso. Acesso em: 27 jul. 2018.

CAMÕES, Luís de. Os Lusíadas. Edição organizada por Emanuel Paulo Ramos. Porto: Porto editora, 1978.

GARRAMUÑO, Florencia. La prosa de la poesia. In: CABANCHIK, Samuel et al. Blog Espacio Murena. 2014, Disponível em: http://www. espaciomurena.com/7892/. Acesso em: 10 ago. 2018

FREITAS, Manuel de. "O tempo dos puetas". Poetas sem Qualidades. Lisboa: Averno. 2002. 
. Cólofon. Lisboa: Fahrenheit 451, 2012.

. Game over. $2^{\mathrm{a}}$ ed. Lisboa: Alambique, 2017.

. Sob o olhar de Neptuno. Porto: Edições 50 kg, 2018.

GUERREIRO, António. Alguns aspectos da poesia contemporânea. Relâmpago - revista de poesia, Lisboa, v. 12, p. 11-18, 2003.

MAFFEI, Luis. O vate de Freitas ou "Camões decerto não se importará". Gragoatá, Niterói, n. 18, p. 307-320, 2005.

MAGALHÃES, Joaquim Manuel. Segredos, Sebes, Aluviões. Évora: Publicação e Dicções, 1981.

MARTELO, Rosa Maria. Anos noventa: breve roteiro da novíssima poesia portuguesa. Via Atlântica, São Paulo, n. 3, 1999.

. Reencontrar o leitor. Relâmpago - revista de poesia, Lisboa, v. 12, p. 39-52, 2003.

PAZ, Octavio. Signos em rotação .Tradução Sebastião Uchoa Leite. São Paulo: Perspectiva, 2009.

PENNA, Ana Beatriz Affonso. Do comércio com as Musas: valor e projeto n' Os Lusíadas e Manuel de Freitas. Darandina Revisteletrônica, Juiz de Fora, v. 5, n. 1, p. 1-17, 2012. Disponível em: https://www.ufjf.br/ darandina/files/2012/06/Valor-e-projeto-final-3.pdf.

SISCAR, Marcos. Poesia e Crise: ensaios sobre a "crise da poesia" como topos da modernidade. Campinas: Editora da Unicamp, 2010.

Recebido em: 24/03/2020

Aprovado em: 06/07/2020 